\title{
Applications of rib sparing technique in internal mammary vessels exposure of abdominal free flap breast reconstructions: a 12-year single-center experience of 215 cases
}

\author{
Qi Zhang ${ }^{1,2 \#}$, Qin Xiao ${ }^{2,3 \#}$, Rong Guo ${ }^{1,2 \#}$, Bingqiu Xiu ${ }^{1,2}$, Lun $\mathrm{Li}^{1,2}$, Weiru Chi ${ }^{1,2}$, Yajia Gu ${ }^{2,3}$, Jiong $\mathrm{Wu}^{1,2,4}$ \\ ${ }^{1}$ Department of Breast Surgery, Breast Cancer Institute, Fudan University Shanghai Cancer Center, Shanghai 200032, China; ${ }^{2}$ Department of \\ Oncology, Shanghai Medical College, Fudan University, Shanghai 200032, China; ${ }^{3}$ Department of Radiology, Fudan University Shanghai Cancer \\ Center, Shanghai 200032, China; ${ }^{4}$ Collaborative Innovation Center for Cancer Medicine, Shanghai 200032, China \\ Contributions: (I) Conception and design: Q Zhang, J Wu; (II) Administrative support: J Wu, Y Gu; (III) Provision of study materials or patients: \\ Q Zhang, Q Xiao, R Guo; (IV) Collection and assembly of data: L Li, W Chi; (V) Data analysis and interpretation: B Xiu, L Li; (VI) Manuscript \\ writing: All authors; (VII) Final approval of manuscript: All authors. \\ "These authors contributed equally to this work. \\ Correspondence to: Jiong Wu, MD, PhD. Department of Breast Surgery, Breast Cancer Institute, Fudan University Shanghai Cancer Center, Building \\ 2, No. 270 Dong An Road, Shanghai 200032, China. Email: wujiong1122@vip.sina.com; Yajia Gu. Department of Radiology, Fudan University \\ Shanghai Cancer Center, Shanghai 200032, China. Email: cjr.guyajia@vip.163.com.
}

Background: Internal mammary vessels (IMVs) are widely used recipient vessels in abdominal free flap breast reconstructions. Rib sparing technique is an alternative method with less damage in IMVs exposure. This study aims to investigate the factors influencing the selection of IMVs, as well as analyze the applicability and related factors of rib sparing technique in abdominal breast reconstruction.

Methods: Medical records of 215 patients who underwent abdominal free flap reconstruction from November 2006 to December 2017 in Fudan University Shanghai Cancer Center (FUSCC) were analyzed. Intercostal space (ICS) was measured from preoperative chest computed tomography scan. Factors influencing the choice of recipient vessels and rib sparing were analyzed. Surgery time, hospitalization and complications were assessed.

Results: Among all 218 flaps, 172 flaps used IMVs as the recipient vessels while 46 used other vessels. patients with immediate reconstruction $(\mathrm{P}=0.005)$ and axillary lymph nodes dissection $(\mathrm{ALND})(\mathrm{P}<0.001)$ were less likely to use IMVs. Patients' body mass index (BMI) and radiotherapy history showed no statistically significant differences between the two groups ( $\mathrm{P}=0.338$ and 0.811$)$. In IMVs group, $62 \%$ cases used rib sparing technique. Compared with rib resection group, patients with rib sparing were taller $(\mathrm{P}=0.047)$ and with a wider ICS $(2.65 \pm 0.54$ vs. $2.25 \pm 0.38 \mathrm{~cm}, \mathrm{P}<0.001)$. Rib sparing group had a shorter surgery and postoperative hospitalization time, as well as a lower complication rate, but the differences were not statistically significant $(\mathrm{P}=0.120,0.450$ and 0.612$)$.

Conclusions: IMVs were used more frequently as the recipient vessels in abdominal free flap breast reconstructions, especially when axillary operation was not performed at the same time. Rib sparing technique had the potential to decrease surgery time, hospitalization days and complications rate. It could be applied in most of the patients with IMVs exposure, particularly in taller patients and patients with a wider ICS. Preoperative chest computed tomography scan can be used to assess the ICS width to provide operational suggestions.

Keywords: Abdominal free flap; breast cancer; breast reconstruction; rib sparing

Submitted May 23, 2019. Accepted for publication Aug 14, 2019.

doi: 10.21037 /gs.2019.08.08

View this article at: http://dx.doi.org/10.21037/gs.2019.08.08 


\section{Introduction}

Abdominal free flap breast reconstruction is the most prevalent practice in autologous breast construction since it has been introduced 30 years ago (1). Internal mammary vessels (IMVs) are preferred recipient vessels for the advantages of larger arterial diameter, less demand for a long pedicle than thoracodorsal vessels and avoidance of axillary scars (2-4). Besides, during exposure, an internal mammary lymph nodes biopsy can be carried out to help instruct oncological treatment (5).

Access to IMVs sometimes needs to resect part of the ribs or costal cartilages to fully expose the vessels (6). This could provide adequate space for operation, but on the other hand often causes post-operation pain, tenderness and contour deformity of the chest wall. In 2008, the rib sparing technique was first introduced and developed fast since then (7).

Previous studies showed that the intercostal space (ICS) was a major factor of conducting rib sparing technique (8). The learning curve of surgeons and equipment used in the operation could also influence the success rate (9). Our center has begun to perform abdominal free flap reconstruction since 2006, and there are more than 200 successful cases by December 2017. Rib sparing technique in IMVs exposure was applied since 2008 and has been used in 68 flaps by the end of 2017. This study included all the abdominal free flaps breast reconstructions done in our center from the beginning to December 2017. We attempted to analyze the related factors of choosing the recipient vessels and using rib sparing technique by comparison.

\section{Methods}

\section{Patients}

From November 2006 to December 2017, all the patients who underwent abdominal free flap breast reconstruction by the same surgeon in Fudan University Shanghai Cancer Center (FUSCC) were involved in the statistical analysis. Patients' age, height, weight, body mass index (BMI) and history of treatment were collected from the medical records. Details of the reconstructions, including surgery time, flap types and complications were recorded by a specially assigned person.

\section{ICS measurement}

Preoperative slice chest CT examinations were performed with the Somatom Definition AS (Siemens Healthcare), the Sensation 64 (Siemens Healthcare), and the Brilliance (Philips Healthcare) using a tube voltage of $120 \mathrm{kV}$ and a current of $200 \mathrm{~mA}$. Images were transferred from the hospital's picture archiving and communication system (PACS) to an off-line workstation. Maximum intensity projection (MIP) and multi-planner reconstructions (MPR) were performed. Raw data were reconstructed with the following standard parameters: slice thickness, $1.0 \mathrm{~mm}$; increment, $1 \mathrm{~mm}$; pitch, 1.078; field of view, $15 \mathrm{~cm}$; and a matrix of $512 \times 512$. The ICS width was measured parallel to the IMVs position recorded in the operation in sagittal reconstructed images, as well as the depth measured from the surface of the pectoralis major muscle to the IMVs. Distance was measured between the parasternal line and IMVs in transverse reconstruction images (Figure 1).

\section{Techniques}

The second and the third ICS was most frequently used. Electrocautery was used to split the pectoralis major muscle along its fibers. The intercostal muscle was incised partly to expose the IM vessels under microscope. The muscle excision to the sternal edge was performed slowly looking for the main vessels (identified by perivascular fat) and carefully ligating vessel branches with micro-clips or Bipoplar. If the ICS was inadequate for comfortable microvascular anastomosis, the costal cartilage was trimmed with a rongeur to create enough space. If the space was already enough, no extra processing of the ribs was required. All the arteries were interrupted anastomosed end-to-end with 9-0 nylon. Veins were end-to-end sutured or used venous coupler for anastomosis.

\section{Outcomes assessment}

The outcomes of rib sparing and rib resection were assessed by surgery time, postoperative hospitalization and complications. The median follow-up time was 18.5 months. Complications that need unplanned reoperation or re-admission were defined as the major complications, including total flap loss, partial flap loss and venous congestion. Minor complications included infection, 

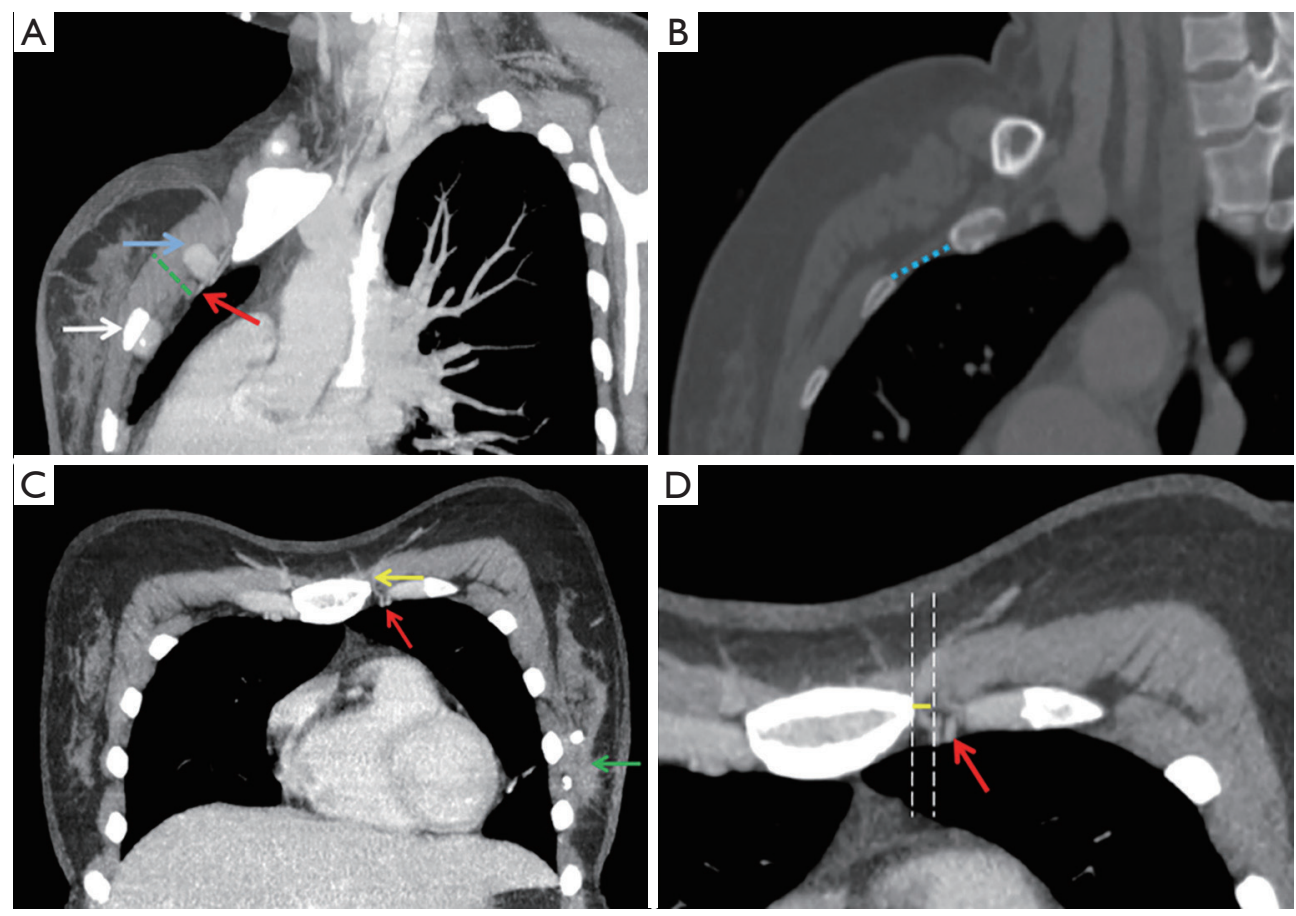

Figure 1 Measurement of intercostal space. (A,B) The internal mammary vessels were marked in sagittal reconstructed images (red arrow), parallel to the position recorded in the operation. The width of ICS (blue line) was measured between the costal cartilage (blue arrow) and the depth (green line) was measured from the surface of the pectoralis major muscle to the IMVs; (C,D) distance (yellow line) was measured between the parasternal line and IMVs in transverse reconstruction images. White arrow: the rib; green arrow: locating clips in breast tumor; yellow arrow: the sternum; red arrows in (C,D): internal mammary vessel. ICS, intercostal space; IMV, internal mammary vessel.

hematoma, fat necrosis and wound problems.

\section{Statistical analysis}

The differences between groups were determined using Pearson's Chi-square tests for categorical variables and $t$-tests for continuous variables. A linear regression analysis was used to determine trends in each parameter over time. All $\mathrm{P}$ values were two-sided. Statistical significance was set at a value of $\mathrm{P}<0.05$. The SPSS program (version 23.0, SPSS, IBM) was used for statistical analysis.

\section{Results}

\section{Patients characteristic and surgery}

From November 2006 to December 2017, 215 patients underwent 218 abdominal-based free flap breast reconstructions by the same surgeon in FUSCC were included. Among which, 56 patients received axillary lymph nodes dissection (ALND) at the same time. The mean patient age was 42.2 years (range, 24-65) and the mean BMI was $22.60 \pm 2.53 \mathrm{~kg} / \mathrm{m}^{2}$ (range, $18.00-33.00$ ). Of these eligible patients, 153 patients received immediate reconstructions while 65 received delayed reconstruction. In all, 16 patients received radiotherapy before breast reconstruction.

\section{Choice of recipient vessels}

Of the 218 flaps, 172 used IMVs as the recipient vessels, 13 used thoracodorsal vessels and 33 used subscapular vessels. To investigate the factors that might influence the choice of IMVs as the recipient vessels, we divided them into two groups based on the recipient vessels used in operation. Age of diagnosis, height, weight, BMI, timing of reconstruction, axillary surgery type and radiation therapy before reconstruction were included into the analysis. As a result, there was no statistical difference between the two groups for age and BMI. Of cases using thoracodorsal and subscapular vessels as recipient vessels, $87 \%$ were 
Table 1 Clinical characteristics by recipient vessels

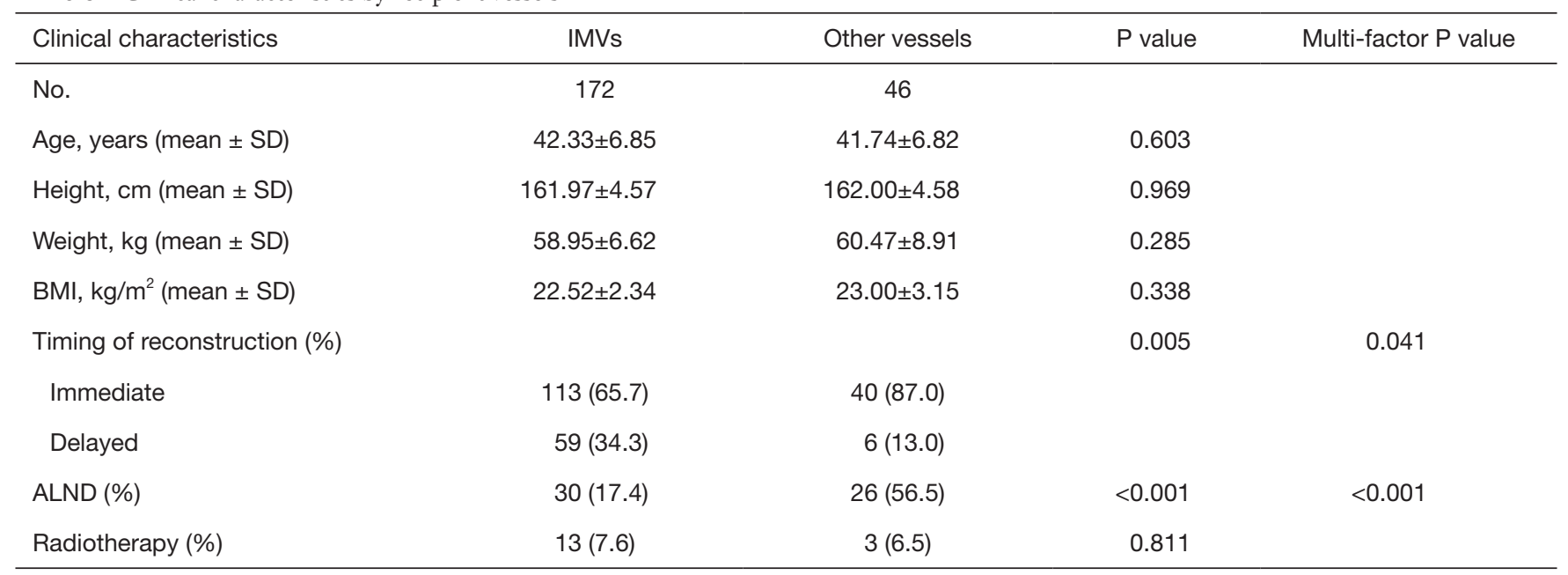

IMVs, internal mammary vessels; BMI, body mass index; ALND, axillary lymph node dissection; SD, standard deviation.
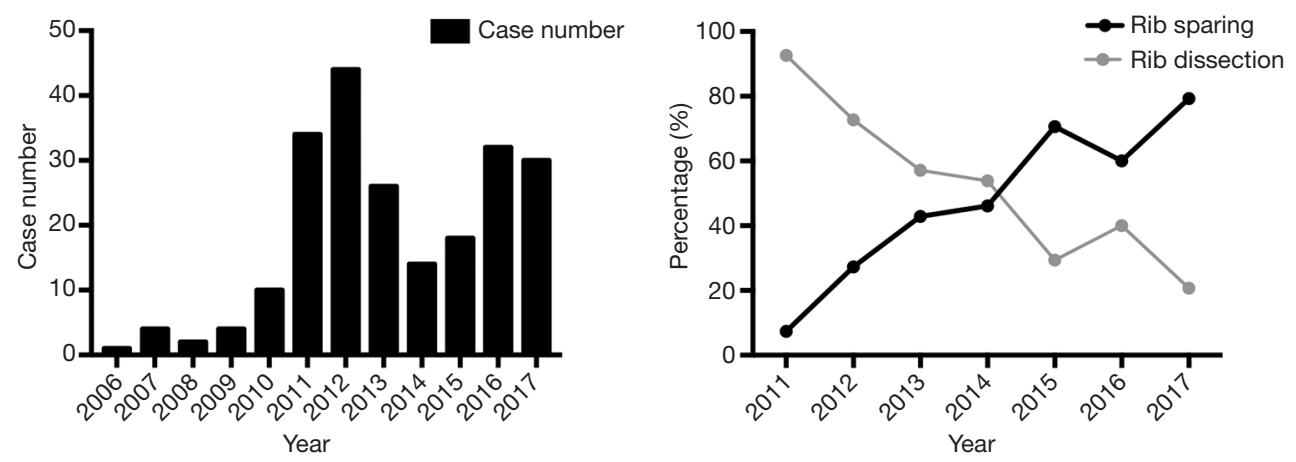

Figure 2 The numbers of abdominal free flap reconstruction surgeries and rib sparing rate in FUSCC each year. FUSCC, Fudan University Shanghai Cancer Center.

immediate reconstructions. As for the IMVs group, 65.7\% were immediate and $34.3 \%$ were delayed reconstructions. It seemed that immediate reconstruction cases were less likely to use IMVs than other vessels as the recipient vessels $(\mathrm{P}=0.005)$. The same trends also showed in cases needing ALND during the surgery, as $56.5 \%$ of the other vessels group had ALND with only $17.4 \%$ in IMVs group $(\mathrm{P}<0.001)$. Patient's height, weight, and radiotherapy history showed no statistically significant differences between the two groups (Table 1). During the operation, the mean ischemia time was 80.01 minutes. For IMVs group, it was $79.97 \pm 31.52$ minutes, and for other vessels group, it was $80.23 \pm 17.03$ minutes. There was no statistical difference in the ischemia time between the two groups $(\mathrm{P}=0.368)$.

\section{Rib sparing technique}

In 172 flaps used IMVs as the recipient vessels, 102 performed rib resection while 70 did not. We observed that the proportion of rib sparing was increased with time, from $7.4 \%$ in 2011 to $79.3 \%$ in 2017 (971.6\% rise; $\left.\mathrm{R}^{2}=0.9109, \mathrm{P}<0.001\right)$. Cases before 2011 were not taken into consideration since there were no more than 10 reconstructions occurred each year (Figure 2).

To further explore the rib sparing technique in IMVs exposure, we allocated the flaps in recent 5 years into rib sparing and rib resection group. Of the 110 cases, 66 were immediate constructions while 44 were delayed. Nine flaps were MS-1 subtype, 52 were MS-2 and 49 were MS-3 
Table 2 Clinical characteristics of patients by rib dealing techniques

\begin{tabular}{|c|c|c|c|c|}
\hline Clinical characteristics & Total & Rib sparing & Rib dissection & $P$ value \\
\hline Age, years (mean $\pm S D)$ & $41.85 \pm 6.95$ & $41.46 \pm 7.97$ & $42.28 \pm 4.90$ & 0.407 \\
\hline Height, cm (mean \pm SD) & $162.90 \pm 4.45$ & $163.57 \pm 4.44$ & $161.83 \pm 4.30$ & 0.047 \\
\hline Weight, kg (mean \pm SD) & $60.08 \pm 6.72$ & $60.03 \pm 5.96$ & $60.17 \pm 7.86$ & 0.918 \\
\hline Flap type (\%) & & & & 0.245 \\
\hline MS-1 & $9(8.2)$ & $4(5.9)$ & 5 (11.9) & \\
\hline MS-2 & $52(47.3)$ & $36(52.9)$ & $16(38.1)$ & \\
\hline MS-3 (DIEP) & $49(44.5)$ & $28(41.2)$ & $21(50.0)$ & \\
\hline Delayed & $44(40.0)$ & $25(36.8)$ & $19(45.2)$ & \\
\hline ALND (\%) & $13(11.8)$ & $10(14.7)$ & $3(7.1)$ & 0.374 \\
\hline Radiotherapy (\%) & $5(4.5)$ & $2(2.9)$ & $3(7.1)$ & 0.304 \\
\hline Venous coupler (\%) & $92(83.6)$ & $54(79.4)$ & $38(90.5)$ & 0.128 \\
\hline Diameter of venous coupler (\%) & & & & 0.156 \\
\hline $1.5 \mathrm{~mm}$ & & $1(1.9)$ & $0(0)$ & \\
\hline $2.0 \mathrm{~mm}$ & & $40(74.1)$ & $25(65.8)$ & \\
\hline $2.5 \mathrm{~mm}$ & & $10(18.5)$ & $10(26.3)$ & \\
\hline
\end{tabular}

*, percentage of patients used venous coupler. MS, muscle sparing; BMI, body mass index; DIEP, deep inferior epigastric perforator flap; ALND, axillary lymph node dissection; $\mathrm{mm}$, millimeter; SD, standard deviation.

[deep inferior epigastric perforator flap (DIEP)]. Thirteen patients received ALND during the surgery. Five patients received previous radiotherapy. In total, 54 cases in ribsparing group and 38 cases in rib resection group used venous coupler during the surgery. The most commonly used venous coupler was $2 \mathrm{~mm}$ in diameter, followed by $2.5 \mathrm{~mm}$.

The patients in the rib sparing group were higher than those in the rib resection group $(163.57 \pm 4.44 v s$. $161.83 \pm 4.30 \mathrm{~cm}, \mathrm{P}=0.047)$. Patients in the rib sparing group had younger age, smaller weight and BMI, but these differences did not achieve statistical significance. There was no statistical difference in flap types between the two groups (Table 2).

Of 110 flaps using IMVs, 103 patients had preoperative thin slice chest CT which allowed us to measure the ICS (92 between the second and third rib cartilages and
11 between the first and second ones). The mean ICS width was $2.65 \pm 0.54 \mathrm{~cm}$ in the rib sparing group and $2.25 \pm$ $0.38 \mathrm{~cm}$ in the rib resection group $(\mathrm{P}<0.001)$. The mean ICS depth was $1.07 \pm 0.22 \mathrm{~cm}$ in the rib sparing group and $1.12 \pm$ $0.21 \mathrm{~cm}$ in the rib resection group $(\mathrm{P}=0.241)$. The mean distance between the parasternal line and IMVs was $1.16 \pm 0.28 \mathrm{~cm}$ in the rib sparing group and $1.12 \pm 0.30$ in the rib resection group $(\mathrm{P}=0.530)$ (Table 3).

\section{Outcome assessment}

The surgery time and postoperative hospitalization was shorter in rib sparing group $(7.39 \pm 1.70$ vs. $7.91 \pm$ 1.73 hours, $\mathrm{P}=0.120 ; 7.43 \pm 2.34$ vs. $7.81 \pm 2.91$ days, $\mathrm{P}=0.450$ ), but the differences were not statistically significant. The total complication rate was $16.2 \%$ in rib sparing group and $21.4 \%$ in rib resection group $(\mathrm{P}=0.612)$, and both the major 
Table 3 ICS related data by rib dealing techniques

\begin{tabular}{lcccc}
\hline Variable & Total & $\begin{array}{c}\text { Rib } \\
\text { sparing }\end{array}$ & $\begin{array}{c}\text { Rib } \\
\text { dissection }\end{array}$ & P value \\
\hline No. & 110 & 68 & 42 & \\
ICS width, cm & & & & $<0.001$ \\
Mean \pm SD & $2.51 \pm 0.53$ & $2.65 \pm 0.54$ & $2.25 \pm 0.38$ & \\
Range & $1.4-3.9$ & $1.4-3.9$ & $1.6-3.1$ & \\
ICS depth*, cm & & & & 0.241 \\
Mean \pm SD & $1.09 \pm 0.22$ & $1.07 \pm 0.22$ & $1.12 \pm 0.21$ & \\
Range & $0.6-1.6$ & $0.6-1.6$ & $0.7-1.6$ & \\
ICS distance ${ }^{* *}, \mathrm{~cm}$ & & & & 0.530 \\
Mean \pm SD & $1.15 \pm 0.29$ & $1.16 \pm 0.28$ & $1.12 \pm 0.30$ & \\
Range & $0.5-2.0$ & $0.6-2.0$ & $0.5-1.9$ & \\
\hline
\end{tabular}

${ }^{*}$, depth: measured from the surface of the pectoralis major muscle to the IMVs. ${ }^{* *}$, distance: measured between the parasternal line and IMVs. ICS, intercostal space.

and minor complication rate were lower in the previous group (Tables 4,5). We also tried to find out if there was a correlation between complications and ischemic time. However, the results showed that neither major nor minor complications nor fat necrosis were associated with ischemic time $(\mathrm{P}=0.565,0.204$ and 0.241$)$.

\section{Discussion}

The selection of suitable recipient vessels in free flap breast reconstruction is crucial for effective surgical outcomes $(10,11)$. Although earlier, the thoracodorsal artery (TDA) and its branches were the preferred recipient vessels, nowadays, IMVs serve as the standard vessels (12). In our practice, the proportion of IMVs as recipient vessels showed a rising trend in general and remained over 90 percent for the recent 3 years. Using IMVs as recipient vessels in a free flap breast reconstruction has already become a common practice. The IMVs usually have larger arterial diameter and less demand for a long pedicle than the thoracodorsal system, which would reduce the requirements for anatomizing the recipient site (13-15). They have higher arterial pressure and large Venturi effect on venous drainage owing to the closer position to cardiac and thus decrease the risk of venous embolism (16). During the surgery, it can allow two surgeons sitting opposite one another to conduct microvascular anastomosis at the same time. Moreover, Using the IMVs spares the thoracodorsal vessels for use in latissimus dorsal flap reconstruction afterwards if the abdominal free flap failed.

Our results showed that of the immediate reconstruction cases, especially when the ALND was carried out during the same time, the thoracodorsal vessels and subscapular vessels were used more frequently than IMVs. This can be explained by the fact that these two vessels were exposed when doing the ALND, so it did not need the extra anatomy of IMVs (17). For the delayed reconstruction cases, some patients had previously axillary dissection, which made it hard to evaluate the condition of the thoracodorsal system, so IMVs were better choice under this situation. Previous study reported that chest-wall irradiation could cause IMVs being fragile and make them unsuitable to be recipient vessels (18). However, here we do not observe the differences of the chosen vessels based on radiotherapy history. This may owe to the small number of radiotherapy cases.

Traditionally, access to IMVs needs the dissection of a segment of the rib or costal cartilage to make fully exposure. Parrett et al. first introduced successfully IMVs preserved with total rib sparing technique in 2008 (7). Our center started to use this technique from 2009. The rib sparing rate increased yearly and maintained over $60 \%$ in the recent 3 years. Additionally, among patients who received rib sparing IMVs exposure in 2017, the mean ICS width was relatively smaller than that in 2013 (2.54 vs. $2.93 \mathrm{~cm}, \mathrm{P}=0.124)$. This indicates that the rib sparing technique has an evident learning curve, but it does not demand a very long time for a surgeon to master it $(8,16,19)$.

By comparing the patients' characteristics of the rib sparing and resection group, we find that only the height of them had a statistical difference. We suggest this may be because the taller patients usually had a wider ICS, which made it easier to expose IMVs. By measuring the used ICS width based on pre-operation chest CT images, we do find that the width of rib sparing group was significantly bigger that the rib resection group $(\mathrm{P}<0.001)$. Kim et al. reported that the IMVs anastomosis can be performed safely in the ICS of at least $15 \mathrm{~mm}$ (20). Our data showed the minimum ICS width in rib sparing group was $1.4 \mathrm{~cm}$, which was basically corresponding with his findings. Since every patient would routinely receive a chest CT scan to evaluate pulmonary situation before surgery, we could use these images to measure the ICS width to help making an operation plan and in no sense increasing patients' financial burden $(8,21)$.

Patients' age, BMI, flap types, axillary surgery type and radiation therapy before reconstruction showed no statistical difference between the two groups, it therefore demonstrates that the rib sparing technique raises no special 
Table 4 Outcomes by rib dealing techniques

\begin{tabular}{lcccc}
\hline Variable & Total & $\begin{array}{c}\text { Rib } \\
\text { sparing }\end{array}$ & $\begin{array}{c}\text { Rib } \\
\text { resection }\end{array}$ & P value \\
\hline $\begin{array}{l}\text { No. } \\
\text { Surgery time, hours }\end{array}$ & 110 & 68 & 42 & \\
$\begin{array}{l}\text { Mean } \pm \text { SD } \\
\text { Range }\end{array}$ & $7.59 \pm 1.72$ & $7.39 \pm 1.70$ & $7.91 \pm 1.73$ & \\
$\begin{array}{l}\text { Postoperative } \\
\text { hospitalization, days }\end{array}$ & $4.5-13.0$ & $4.5-13.0$ & $5.0-12.0$ & \\
$\begin{array}{l}\text { Mean } \pm \text { SD } \\
\text { Range }\end{array}$ & & & & 0.450 \\
$\begin{array}{l}\text { Total } \\
\text { complications (\%) }\end{array}$ & $20(18.2)$ & $11(16.2)$ & $9(21.4)$ & 0.612 \\
\hline
\end{tabular}

SD, standard deviation.

demands for the patients and can be widely applied in IMVs exposure in free flap breast reconstruction.

When it comes to the outcomes, the rib sparing group had less surgery time and hospitalization days. Since surgery time and hospital stay are usually associated with vascular complications and infection (22-24), and the follow up also revealed that the rib spring group had lower total complications rate, we suggest that the rib sparing technique is safer than rib resection.

In some cases, rib resection needs to be carried out when the exposure is inadequate for safe and comfortable microvascular anastomosis, or be used to extend the exposure distance of IMVs when the diameter of the vessels, especially that of the veins is mismatching (20). Sometimes, during IMVs anatomy, the vessels will be damaged or found thrombosis in anastomotic sites, resulting to the resection of ribs and re-anastomosis (25). Research revealed that difficulties of anastomosis during operation easily lead to postoperative vascular complications (26). This might explain why the patients underwent rib resection were more likely to have serious complications of the flaps. Additionally, studies showed that patients undergoing free flap breast reconstruction with rib sparing experienced less postoperative pain and had less thoracic deformity compared to those with rib resection $(7,27,28)$. All these evidences indicate that the rib sparing technique is a less invasive technique and would benefit patients more.

In conclusion, our study revealed that IMVs are more popular choice as the recipient vessels in abdominal free flap breast reconstructions, especially when there is no axillary operation carried out at the same time. Rib sparing technique with less surgical damage may have the potential to decrease surgery time and hospitalization days, as well as decrease the probability to have severe complications. It could be used in most of the patients received free flap reconstruction when IMVs were used, particularly in taller patients and patients with a wider ICS.

There are some limitations in this study. Since all the reconstructions were performed by the same surgeon, the generalizability of our findings might be limited. Other limitations include the relatively small size of study cohort and the lack of patient-reported outcomes. Longer term and prospectively designed studies on this topic may give further clinical indications.

Table 5 Complications by rib dealing techniques

\begin{tabular}{lll}
\hline Variable & Rib sparing & Rib resection \\
\hline No. & 68 & 42 \\
Major complications (\%) & $5(7.4)$ & $4(9.5)$ \\
& Partial flap loss $(\mathrm{n}=3) ;$ & Total flap loss $(\mathrm{n}=1) ;$ \\
& venous congestion $(\mathrm{n}=2)$ & partial flap loss $(\mathrm{n}=2) ;$ \\
& & venous congestion $(\mathrm{n}=1)$
\end{tabular}




\section{Conclusions}

The IMVs exposure with rib sparing technique is a less invasive method and can be widely used in abdominal free flap breast reconstruction. In addition to its no strict demands for both patients' characteristics and surgeons' skills, it also has the advantages to decrease surgery time, hospital stay and severe complications rate. Preoperative slice chest CT scan can be used to measure the ICS width to provide suggestions for dealing with the ribs.

\section{Acknowledgments}

None.

\section{Footnote}

Conflicts of Interest: The authors have no conflicts of interest to declare.

Ethical Statement: The authors are accountable for all aspects of the work in ensuring that questions related to the accuracy or integrity of any part of the work are appropriately investigated and resolved. The study was approved by the Medical Ethics Committee of Fudan University Shanghai Cancer Center, Shanghai, China. The approval number was 1905202-7. Because this was a retrospective study involving only basic demographic data of patients and surgical information, there was no paperbased informed consent.

\section{References}

1. Shaw WW. Microvascular free flap breast reconstruction. Clin Plast Surg 1984;11:333-41.

2. Chang EI, Chang EI, Soto-Miranda MA, et al. Demystifying the use of internal mammary vessels as recipient vessels in free flap breast reconstruction. Plast Reconstr Surg 2013;132:763-8.

3. Quaba O, Brown A, Stevenson H. Internal mammary vessels, recipient vessels of choice for free tissue breast reconstruction? Br J Plast Surg 2005;58:881-2.

4. Moran SL, Nava G, Behnam AB, et al. An outcome analysis comparing the thoracodorsal and internal mammary vessels as recipient sites for microvascular breast reconstruction: a prospective study of 100 patients. Plast Reconstr Surg 2003;111:1876-82.

5. Yu JT, Provenzano E, Forouhi P, et al. An evaluation of incidental metastases to internal mammary lymph nodes detected during microvascular abdominal free flap breast reconstruction. J Plast Reconstr Aesthet Surg 2011;64:716-21.

6. Majumder S, Batchelor AG. Internal mammary vessels as recipients for free TRAM breast reconstruction: aesthetic and functional considerations. Br J Plast Surg 1999;52:286-9.

7. Parrett BM, Caterson SA, Tobias AM, et al. The ribsparing technique for internal mammary vessel exposure in microsurgical breast reconstruction. Ann Plast Surg 2008;60:241-3.

8. Kim H, Lim SY, Pyon JK, et al. Preoperative computed tomographic angiography of both donor and recipient sites for microsurgical breast reconstruction. Plast Reconstr Surg 2012;130:11e-20e.

9. Malata CM, Moses M, Mickute Z, et al. Tips for successful microvascular abdominal flap breast reconstruction utilizing the "total rib preservation" technique for internal mammary vessel exposure. Ann Plast Surg 2011;66:36-42.

10. Clark CP 3rd, Rohrich RJ, Copit S, et al. An anatomic study of the internal mammary veins: clinical implications for free-tissue-transfer breast reconstruction. Plast Reconstr Surg 1997;99:400-4.

11. Baek IS, You JP, Rhee SM, et al. A clinical anatomic study of internal mammary perforators as recipient vessels for breast reconstruction. Arch Plast Surg 2013;40:761-5.

12. Vollbach FH, Heitmann CD, Fansa H. An Appraisal of Internal Mammary Artery Perforators as Recipient Vessels in Microvascular Breast Reconstruction-An Analysis of 515 Consecutive Cases. Plast Reconstr Surg Glob Open 2016;4:e1144.

13. Halim AS, Alwi AA. Internal mammary perforators as recipient vessels for deep inferior epigastric perforator and muscle-sparing free transverse rectus abdominis musculocutaneous flap breast reconstruction in an Asian population. Ann Plast Surg 2014;73:170-3.

14. Murray AC, Rozen WM, Alonso-Burgos A, et al. The anatomy and variations of the internal thoracic (internal mammary) artery and implications in autologous breast reconstruction: clinical anatomical study and literature review. Surg Radiol Anat 2012;34:159-65.

15. Beebe DP, Miles LA, Plow EF. A linear amino acid sequence involved in the interaction of t-PA with its endothelial cell receptor. Blood 1989;74:2034-7.

16. Rosich-Medina A, Bouloumpasis S, Di Candia M, et al. Total 'rib'-preservation technique of internal mammary vessel exposure for free flap breast reconstruction: A 5-year 
prospective cohort study and instructional video. Ann Med Surg (Lond) 2015;4:293-300.

17. Santanelli Di Pompeo F, Longo B, Sorotos M, et al. The axillary versus internal mammary recipient vessel sites for breast reconstruction with diep flaps: a retrospective study of 256 consecutive cases. Microsurgery 2015;35:34-8.

18. Temple CL, Strom EA, Youssef A, et al. Choice of recipient vessels in delayed TRAM flap breast reconstruction after radiotherapy. Plast Reconstr Surg 2005;115:105-13.

19. Butler PD, Wu LC. Abdominal perforator vs. muscle sparing flaps for breast reconstruction. Gland Surg 2015;4:212-21.

20. Kim H, Lim SY, Pyon JK, et al. Rib-sparing and internal mammary artery-preserving microsurgical breast reconstruction with the free DIEP flap. Plast Reconstr Surg 2013;131:327e-34e.

21. Fitzgerald O'Connor E, Rozen WM, Chowdhry M, et al. Preoperative computed tomography angiography for planning DIEP flap breast reconstruction reduces operative time and overall complications. Gland Surg 2016;5:93-8.

22. Duraes EF, Schwarz G, Durand P, et al. Complications Following Abdominal-Based Free Flap Breast Reconstruction: Is a 30 days Complication Rate Representative? Aesthetic Plast Surg 2015;39:694-9.

Cite this article as: Zhang Q, Xiao Q, Guo R, Xiu B, Li L, Chi W, Gu Y, Wu J. Applications of rib sparing technique in internal mammary vessels exposure of abdominal free flap breast reconstructions: a 12-year single-center experience of 215 cases. Gland Surg 2019;8(5):477-485. doi: 10.21037/gs.2019.08.08
23. Wade RG, Razzano S, Sassoon EM, et al. Complications in DIEP Flap Breast Reconstruction After Mastectomy for Breast Cancer: A Prospective Cohort Study Comparing Unilateral Versus Bilateral Reconstructions. Ann Surg Oncol 2017;24:1465-74.

24. Chang SY, Huang JJ, Tsao CK, et al. Does ischemia time affect the outcome of free fibula flaps for head and neck reconstruction? A review of 116 cases. Plast Reconstr Surg 2010;126:1988-95.

25. Chang EI, Mehrara BJ, Festekjian JH, et al. Vascular complications and microvascular free flap salvage: the role of thrombolytic agents. Microsurgery 2011;31:505-9.

26. Fosnot J, Jandali S, Low DW, et al. Closer to an understanding of fate: the role of vascular complications in free flap breast reconstruction. Plast Reconstr Surg 2011;128:835-43.

27. Mickute Z, Di Candia M, Moses M, et al. Analgesia requirements in patients undergoing DIEP flap breast reconstructions: rib preservation versus rib sacrifice. J Plast Reconstr Aesthet Surg 2010;63:e837-9.

28. Sacks JM, Chang DW. Rib-sparing internal mammary vessel harvest for microvascular breast reconstruction in 100 consecutive cases. Plast Reconstr Surg 2009; $123: 1403-7$. 